\title{
The teaching of geography
}

\section{Elisée Reclus}

To cite this article: M. Elisée Reclus (1901) The teaching of geography, Scottish Geographical Magazine, 17:8, 393-399, DOI: 10.1080/00369220108733271

To link to this article: http://dx.doi.org/10.1080/00369220108733271

册Published online: 27 Feb 2008.

Submit your article to this journal $\widetilde{1}$

III Article views: 15

Q View related articles $\asymp$ 


\title{
THE SCOTTISH
}

\section{GE O G R A P H I A L}

MAGAZINE.

\section{THE TEACHING OF GEOGRAPHY:}

\author{
Globes, Discs, AND Reliefs.
}

By M. Elisté Reclus.

TuE teaching of Geography, without which all other studies lack the vital element which is their visible, tangible, and ever-changing framework, can be effectively performed in its concrete reality by the observation of nature alone.

The subject of the first lessons, of those whose effects are most durable and of the greatest consequence in the spiritual and moral development of the child, is to show directly the Earth in all its cosmical connections and physical aspect, in its daily, monthly, and yearly movements. We make the child attentive to the succession of days and nights, to the course of the sensons, with their alternation of heat and cold, of winds and calms, of storms, rains, and droughts, to the flow of the waters, that never-ceasing force perpetually engaged in the sculpture of the landscape.

This method of teaching, from which are derived at the same time health and enjoyment, can unhappily be practised but little in our large cities, standing so to speak apart from nature, but the shortest walk outside the walls of the school may be utilised by the teacher to show to his young friends, for the benefit of their instruction, the agents actually at work, were it only the form of passing clouds or the ever-changing forms of sand and mud deposits which are shaped by the wind and the rain in the street gutters.

Even if those who study Geography were able to travel all over the Earth and to study every one of its mysteries on the very spot where it is best observed, they could not do without a model of our planet. They must have some concrete frame, in which the result of their

voL. XVII. 
researches may be classified and the undisputed facts recorded. They must be able to localise their impressions and knowledge, have a clear idea of the relative position of the forms and distances of all the parts of the Earth, and have the means of comparing the countries they have heard of with those they know.

That representation of our planet cannot be anything but a sphere, exactly shaped like the large spheroidal ball which carries us in space. No map on a flat surface, however carefully drawn, can take the place of a globe. It is impossible to give to a plane figure the character of truthfulness, which a representation of the Earth must have, especially for children whose inquisitive minds cannot be satisfied by technical explanations of the projection of maps.

Before a globe there is no feeling of mystery. The child, who must naturally be bewildered by a map of the whole world on a single sheet of paper, understands at first sight a globe in which he sees a simple reduction of the large globe of which he has been told.

Thus a globe, upon which each hundredth of a millimetre represents a kilometre on the earth's surface, is unmistakably the figure of our earth to the scale of one to one hundred million $(1: 100,000,000)$. While our planet is 40,000 kilometres in circumference, that tiny reproduction is only 0.4 metre; nevertheless, on its curve the continents keep their real aspect; forms are respected as well as directions, distances, and pro- portion of areas. Harmony of nature is not modified in any way, and study is rewarded with immediate comprehension.

Before a map representing on the flat a large area, confusion of thought is inevitable, and impressions are wrong; and they are wrong in proportion to the extent of area of which the map is supposed to give a drawing. The reader remains perforce misled, especially when the map deals with distant countries whose form he is not familiar with. The very map which ought to be his guide deceives him, and, worst of all, he cannot know what is the nature of the errors which he has to correct. - He consequently and naturally lapses into indifference towards the diversely shaped reproductions put before him. Knowing that he cannot get one truthful map, he does not care what forms he looks on. One method of projection enlarges the central part of the map, another the outlying districts, a third one draws out the peninsulas as if they had been passed through the rolling-mill, a fourth will, on the contrary, spread them, as if every part of the Earth surface were a sheet of elastic matter which could be at will pulled out or shrunk in all directions. In the study of every map it would be necessary to take into account the error introduced in every one of its parts by the projection of the network; but however accustomed to mental calculation, however well trained in the study of maps, the reader cannot help being influenced by the foreshortened outlines which he considers. The image kept in one's mind is always wrong, and sometimes the very geographer who is most accustomed to map-reading is the person whose brain is most helplessly muddled as to forms of natural features.

Therefore it is first for the sake of truthfulness that the representa- 
tion of the planet must be done in the form of globes and not in the form of flat maps. A second advantage offered by the spherical figure is the character of unity. The common practice of studying one's own country on large-scaled maps and distant countries on much smaller scaled and proportionally incomplete maps keeps alive in the reader's mind delusions which the scientist shares too often. The Swiss, the Belgians, the Dutch must study the hard facts of statistics to realise that another country, whose map they have never seen in a larger size than the one of their native land, is really ten or a hundred times larger. On the curved surface of a globe no mistake is ever possible. The areas are to be seen side by side, and at the very outset comparison is made in the mind with sufficient accuracy.

There is no possible doubt : the spherical form is the one which must be used at first in teaching; but beyond a certain scale globes become very awkward implements by the space they claim. Sheets of paper can be piled up or bound together, a set of drawers can contain hundreds and thousands of them, but globes, even small, claim a definite space, and are, moreover, generally complicated with stands and circles, which make them cumbrous instruments at the best. That explains how globes have fallen into disfavour. The making of globes, which was more common than is generally believed at the time of the great geographical discoveries and during the two following centuries, has been now for many years almost confined to the production of globes rarely more than one foot in diameter. ${ }^{1}$ The celebrated sphere of Martin Behaim (now in the library of Nürnberg) which Columbus saw, and on which he clearly perceived how his voyage could be accomplished, is bigger, its diameter being 52 centimetres ( $20 \frac{1}{2}$ inches), which after all is a very small thing.

As Ovid said :

$$
\text { "Stat globus, immensi parva figura poli." }
$$

Truly our world is immense, the representation is very small, nevertheless is it sufficient to sum up all human knowledge and to leave in the mind of the children a final impression of truth.

We must not forget that such skilful artists as Olearius and Coronelli built terrestrial and celestial globes of far greater dimensions, but these big monuments, having 3,4 , and up to 5 metres diameter, were not looked upon as instruments of teaching, but simply considered as curios for the decoration of palaces.

It is only in our own days that the usefulness to science of largesized globes has been understood. In some future period globes of

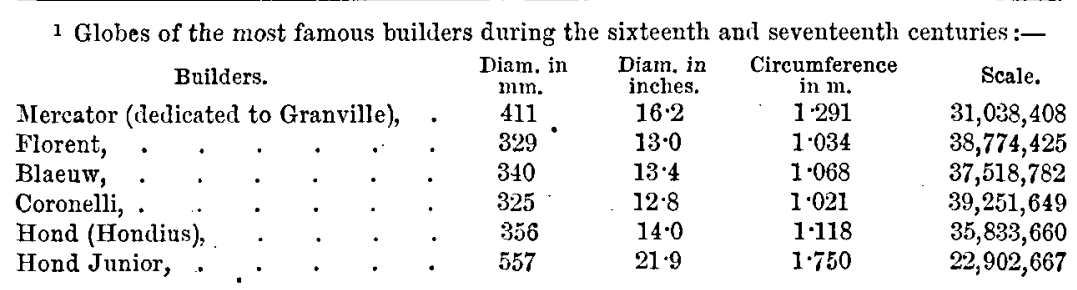


large dimensions and of rigorous detailed construction, at the scale of $1: 1,000,000$, or $1: 500,000$, or even $1: 100,000$ will not unlikely show their spherical dome in the parks of our large agglomerations, and be possibly disposed in such a way that the general aspect of the whole and the local study of the detail may be permissible. Considering the powerful resources of modern industry and the general trend of public opinion; we have the greatest hope that the erection of such a wonderful construction-one day a necessary part of the scientific outfit of every large centre-will be attempted at no very far distant date. Meanwhile our schools must be satisfied with very modest spheres; an ordinary limit will be the scale $1: 20,000,000$, giving a sphere of two metres circumference-in some special cases spheres for teaching purposes may reach the scale $1: 10,000,000-4$ metres round the equator, and only in the large halls of our universities could globes at the scale of one to the million be constructed-globes having nearly 13 metres diameter. The scale $1: 1,000,000$ recommends itself in another way; it is the size which will allow the relief of the soil modelled to its true scale of being seen, perhaps not very conspicuously, but at least clearly : the Himalaya showing a ridge of 8 millimetres $\left(=\frac{1}{3}\right.$ of an inch) above the valley of the lower Ganges.

These globes would have over old ones the advantage of being constructed according to a definite scale, a thing which was impossible before Picard, Maupertuis, and La Condamine had measured ares of meridian, thus ascertaining the real size of the Earth. At the time of Mercator, the founder of modern cartography, the Earth's circumference was still evaluated at 5400 German leagues, nearly 50000 kilometres of our day, or at a quarter more than measurements proved it to be.

As we cannot take spheres of big dimensions into our rooms, why should we not cut such balls into fragments easy to handle? If a real globe be divided, the parts could not be all of the same shape, but by allowing overlapping of contiguous pieces, they might all be extended into equal-sized, preferably circular, discs: A globe to the scale of one to $10,000,000$ can in that way be replaced by, say, forty discs of the ordinary size of flat maps, discs having the same external form, the same size, and the same curvature, and which therefore can easily be piled up or bound in an atlas. We get thus a complete one-scaled atlas taking the place of so many maps with as many different scales or without any possible scale. In the same way the globe showing the Earth's surface to 1:5,000,000-a larger scale than is ordinarily used for countries outside of Europe-would give an atlas of about 150 globular maps of usual size. From these 150,10 perhaps would not yet be/ mapped, as belonging to Antarctic regions. Each disc overlapping its neighbour all round the circle, no earthly point can be left unrepresented. Perhaps three-fifths of these 150 discs would represent sea-regions, and might be classified apart.

It has been said with reason from Gerard Mercator that he had been the providence of pilots. Thanks to his charts, imagined in 1569, the mariner could draw a straight line between his starting-point and 
his destination, read the course (direction), and sail away with the help of stars and compass. In our days, when great circle sailing has been inaugurated together with the introduction of steam, the globular discs may play the same rôle in relation to time-saving sailing, as did the maps of Mercator to the navigation of former days. We have, it is true, the gnomonic charts, issued by the Hydrographic Office of the U.S.A., on which every great circle-sailing track shows as a straight line, but course and distance can only be got by an elaborate process, whereas globular charts would give, with the help of an appropriate ruler, track, course and distance at a single glance.

The advantages of a globe cut thus into fragments would be exactly the same as those of a whole globe; the circular sections have the same character of truth and unity; it would only be needed to adjust them side by side, taking overlapping into consideration, to reconstitute the globe in part or in its entirety. To our mind it would be a very fitting decoration for our public halls to see such discs hanging on the walls, as did shields in the bygone age of war, dises showing in the midst of blue oceans the curved surface of the big continental masses from Europe to the unknown Antarctic. The geographer might have then full right to compare the beanty of his work with that produced by artists, painters, sculptors, or ceramists.

Obviously there is nothing new in the idea. In all times there have been proposals made to represent different countries by means of rounded surfaces showing the exact curvature, and giving thus at least an approximate idea of their true surface, compared with that of the Earth. In some museums, we can even admire the splendid map of Signor Pomba, which shows so beautifully the relief of Italy, from Sicily to the summit of the Alps. But up to now these reliefs can only be got at high prices by means of moulds and casts.

New industrial methods, however, give to the geographer the means of bending a disc of metal, cardboard, or celluloid to the exact mathematical curvature required by the scale, and to have on that disc a perfect engraving printed according to the best rules of cartography. Any number of copies can be obtained in that way. The price of the raw material will be higher than that of paper; but, on the other hand, it has the great advantage of being far less sensible to atmospheric changes of dryness and dampness, and the draughtsman who works on a map to be printed on a spherical disc will be inclined to do it with a care correspondingly greater, as the printed surface is less perishable."

As soon as the scale of the map on the curved surface is large

1 The discs are circular portions of a sphere to the required scale extended into a square by a flat border; the map is drawn, engraved, and coloured on the flat as usual, then printed on flat sheets of metal. These sheets in turn are submitted to a powerful pressure in a mould specially devised by. Mr. E. Patesson, which brings them to the required shape without the slightest crease. One of the interesting points in that mechanical action is the regular modification which the network undergoes. When drawn on the flat, its deformation must be foreseen, so as to come out on the bent metal as portions of perfect great circles and of parallels, intersecting everywhere one another at right augles. 
enough for the curvature to be perceptible to the eye, the cartographer is confronted with another geographical problem : he has to show the relief, pimples and dimples of the terrestrial orange, not symbolically, not by contour-lines, hachures, or scales of colours, but directly through an actual relief absolutely proportioned to the exact form of nature.

I take it to be an absolute rule that the relief must be given at the same scale as the map which is used as base, or in other words, the scale must be the same for horizontal and vertical lengths. Any relief which cannot be shown without exaggeration had better be left unrepresented, because any departure from the general rule will lead to misunderstandings and errors. False impressions are the more lasting, as they are partly based on a more scientific basis-a beautiful relief, the vertical scale of which is exaggerated in a certain proportion, will mislead for ever the cleverest scientist.

Our museums and schools of geography are already rich in beautiful reliefs modelled on true scales. These reliefs deal with districts which their natural beauty or their historical development render especially interesting. Some districts of the Alps and Pyrenees, some islands like Porquerolles, Iona, Rügen, some volcanoes and peaks like Vesuvius, Teneriffe, Arthur's Seat, the environs of some capitals and of some pleasure resorts, have been built and carved with the greatest skill. But a complete series of reliefs representing methodically the portion of the Earth's surface which geometers have carefully surveyed and drawn, about onetenth of the land above water, that. work has not yet been begun. Nevertheless it must be done, if the teaching of Geography is ever to rest on the exact figure of the Earth, and not upon incomplete representation appealing insufficiently to the eye and to the intellect.

As I have already mentioned, the scale $1: 1,000,000$ is the smallest one at which reproduction of terrestrial relief can be attempted; a height of 1000 metres ( $=3000$ feet) will be represented by 1 millimetre on the artificial globe, even half that height will be sensible, especially so if the cast is lit by a horizontal light. Thus on a sphere of 40 metres circumference will be shown all the important orographical systems which form the general skeleton of the continents, also isolated peaks like Gibraltar, Athos, Ailsa Craig, would peep clearly above the level of the water.

Upon a globe or fragment of a globe, at the same rate as the scale increases, there increases also the evidence of terrestrial life. We cannot but feel this at the sight of the admirable work which Mr. Perron, the Genevan cartographer, has carved, the relief of the Swiss Alps from Mont Blanc to the Bernina, to the scale of $1: 100,000$, upon a length quite sufficient to make sensible the curvature of the Earth. In looking at it, it seems as if one could see the geological factors at work, the production of folds and faults, the erosion, denudation, and deposition, and so on. To that scale a large relief gives already the impression of nature itself. It is like travelling in an air-ship above the mountaintops; under your feet you see combes, glens, valleys, and plains; you see long ranges and ridges stretching far away, suddenly interrupted in the distance and reappearing farther away along lines which the study of 
the map had not led to suspect. In that solemn contemplation you participate so to speak with eternity; it is like seeing a portion of the Earth evolving out of the primitive mass under the action of the shaping elements which are still at work.

And the wonderful effects obtained by such scales are still increased in larger-scaled reliefs, $1: 50,000,1: 10,000$, and so on. Of course the modest parish school could not attempt to possess all these treasures, if they were to be obtained, as to-day, by long and costly processes which at the most can give a few specimens for richly endowed museums. But here also industry comes to our help. In the same way as we can provide spherical discs in an unlimited number of copies, we are given the promise of thousandfold and millionfold exact reproductions of terrestrial reliefs. Not a single classroom will be then without truthful images of the most beautiful regions of the Earth, of those where the most remarkable features are to be seen and the most interesting phenomena to be studied.

Thanks to these lifelike reliefs, which will be found everywhere and which every child will see, we shall return to the direct study of nature; the teaching of Geography will revert to the method with which it started. The child will draw his own and immediate conclusions from the very source of our knowledge-the contemplation and study of our mother Earth.

\section{THE FIRST TOPOGRAPHICAL SURVEY OF SCOTLAND.}

\section{By C. G. CASH, F.R.S.G.S.}

THE recent publication in the Scotsman of two articles on the Ordnance Survey (September 18 and 25, 1900) has drawn attention to several matters of interest and importance in the history of Scottish Topography, and, among others, especially to the preparation and publication of the first topographical survey of Scotland. This great and notable work was executed during the last part of the sixteenth and the first half of the seventeenth centuries, and it seems strange that up to the present no adequate and accurate account of it has been published, nor indeed any account at all that is readily accessible to the general reader or to the student who cannot get to the limited publications of certain learned and exclusive societies. Possibly an adequate account cannot yet be written, for there is a lack of information in regard to several material points; but it should be possible to give an account that avoids any positive inaccuracy, and such an account I hope here to present.

The men to whose ability, energy, and devotion the survey was due have not received the recognition that is their right; and neither is there to their honour any memorial even in the hall of the Royal Scottish Geographical Society, nor are the manuscripts of their work treated with the care and respect that should be bestowed on such sacred relics. I propose in this article to collect what is known of this survey and of the men that made it, and so to point out the extent of the indebtedness of 